\title{
WLAN oriented optimization of process bus in IEC 61850-based substation communication network
}

\begin{abstract}
The communication standard IEC 61850 which is defined for information exchange in smart grids, has been increasingly used for Substation Automation Systems (SAS). Current mainstream communication technologies such as switched Ethernet and TCP/IP have been adopted for the communications networking. However, with the growing amount of IEDs in one collision domain, a risk of violation of transmission time requirement increases. This raises a concern for optimization of IEC 61850 based substation communication network. The industrial wireless LAN technologies are gaining interest power utility sector, especially for less critical smart distribution network applications. This paper proposes methods of software simulation for performance evaluation of communications network in power substations. This method enables to test the performance of process bus only using Sampled Value (SV) and obtains a maximum number of WLAN IEDs in one collision domain subject to various conditions.
\end{abstract}

Keyword: IIEC-61850; Process bus; Sampled value; Simulation; Smart grids; Substation communication 